Supplement of Hydrol. Earth Syst. Sci., 21, 2163-2185, 2017

http://www.hydrol-earth-syst-sci.net/21/2163/2017/

doi:10.5194/hess-21-2163-2017-supplement

(C) Author(s) 2017. CC Attribution 3.0 License.

(c) (i)

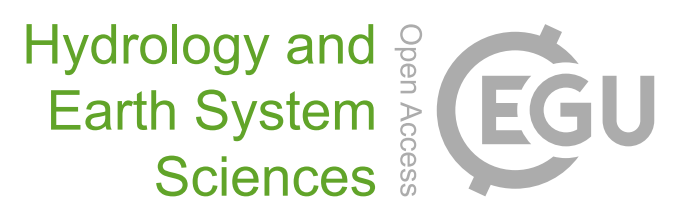

Supplement of

\title{
Inter-comparison of daily precipitation products for large-scale hydro-climatic applications over Canada
}

Jefferson S. Wong et al.

Correspondence to: Jefferson S. Wong (jefferson.wong@usask.ca)

The copyright of individual parts of the supplement might differ from the CC-BY 3.0 licence. 


\section{List of Supplementary Tables}

Table S1 Number of precipitation-gauge stations within each major drainage area.

\begin{tabular}{|l|c|c|c|}
\hline \multirow{2}{*}{ Region (Major Drainage Area) } & \multicolumn{2}{c|}{ Number of Precipitation-gauge Stations } \\
\cline { 3 - 4 } & Maritime Provinces & 5 & $2002-2012$ \\
\hline 1 & St. Lawrence & 26 & 26 \\
\hline 2 & Great Lake & 13 & 11 \\
\hline 3 & Newfoundland & 3 & 2 \\
\hline 4 & Northern Quebec and Labrador & 4 & 5 \\
\hline 5 & Southwestern Hudson Bay & 3 & 4 \\
\hline 6 & Nelson River & 22 & 19 \\
\hline 7 & Great Slave Lake & 7 & 7 \\
\hline 8 & Western and Northern Hudson Bay & 8 & 8 \\
\hline 9 & Pacific & 43 & 41 \\
\hline 10 & Yukon & 5 & 3 \\
\hline 11 & Arctic & 3 & 2 \\
\hline 12 & Mackenzie & 2 & 1 \\
\hline 13 & Mississippi & 1 & 137 \\
\hline 14 & Total & 145 & \\
\hline & & & 3 \\
\hline
\end{tabular}




\section{List of Supplementary Figures}

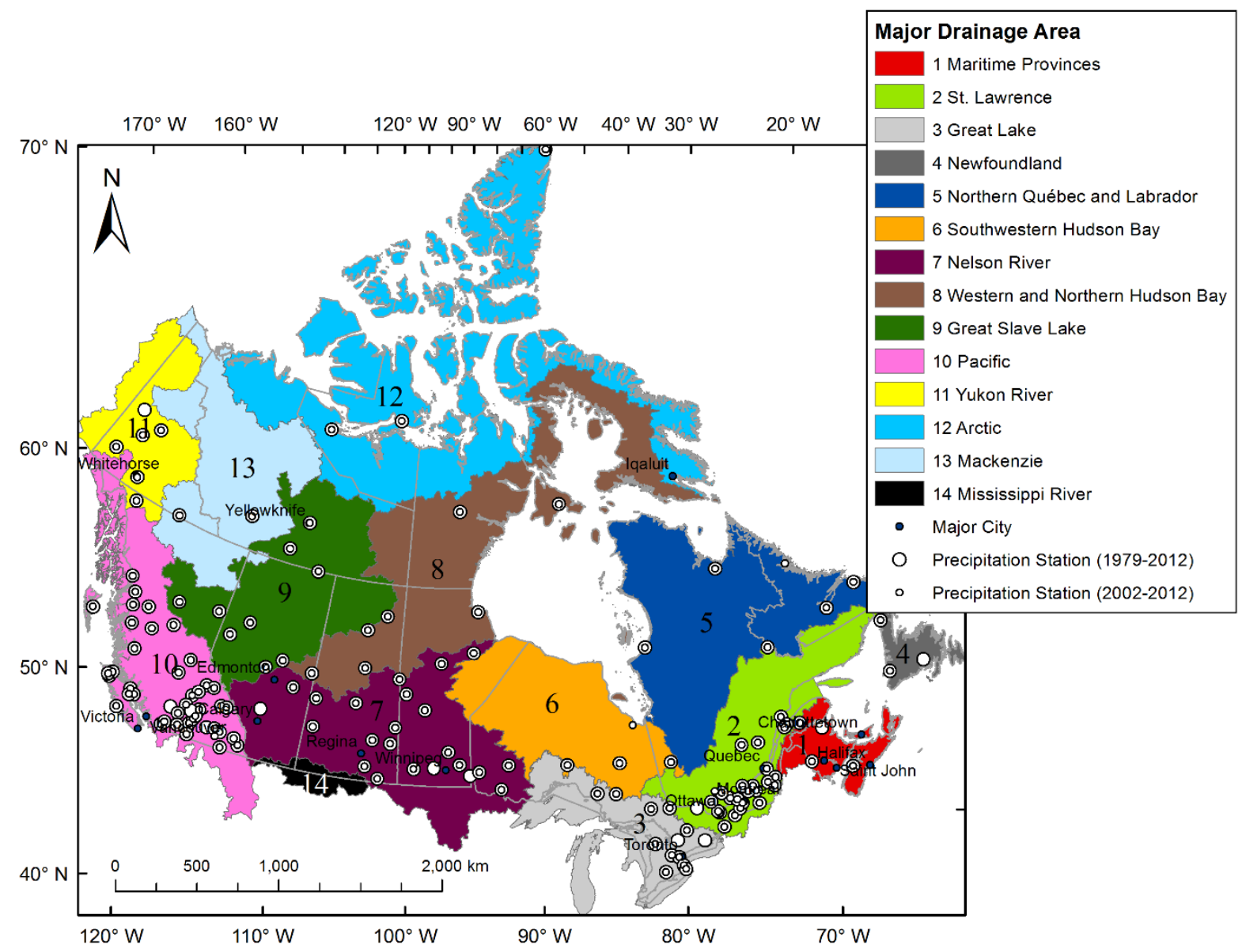

Figure S1. 14 major drainage areas of Canada with numerical codes indicating Region from 1 Maritime Provinces to 14 Missisippi River. Big (a total of 145) and small (a total of 137) white dots are the extracted precipitation-gauge stations from the Canadian adjusted and homogenized precipitation datasets of Mekis and Vincent (2011) for the period of 1979 to 2012 and 2002 to 2012 respectively. Black dots are majot cities in Canada. 
$1979-2012$
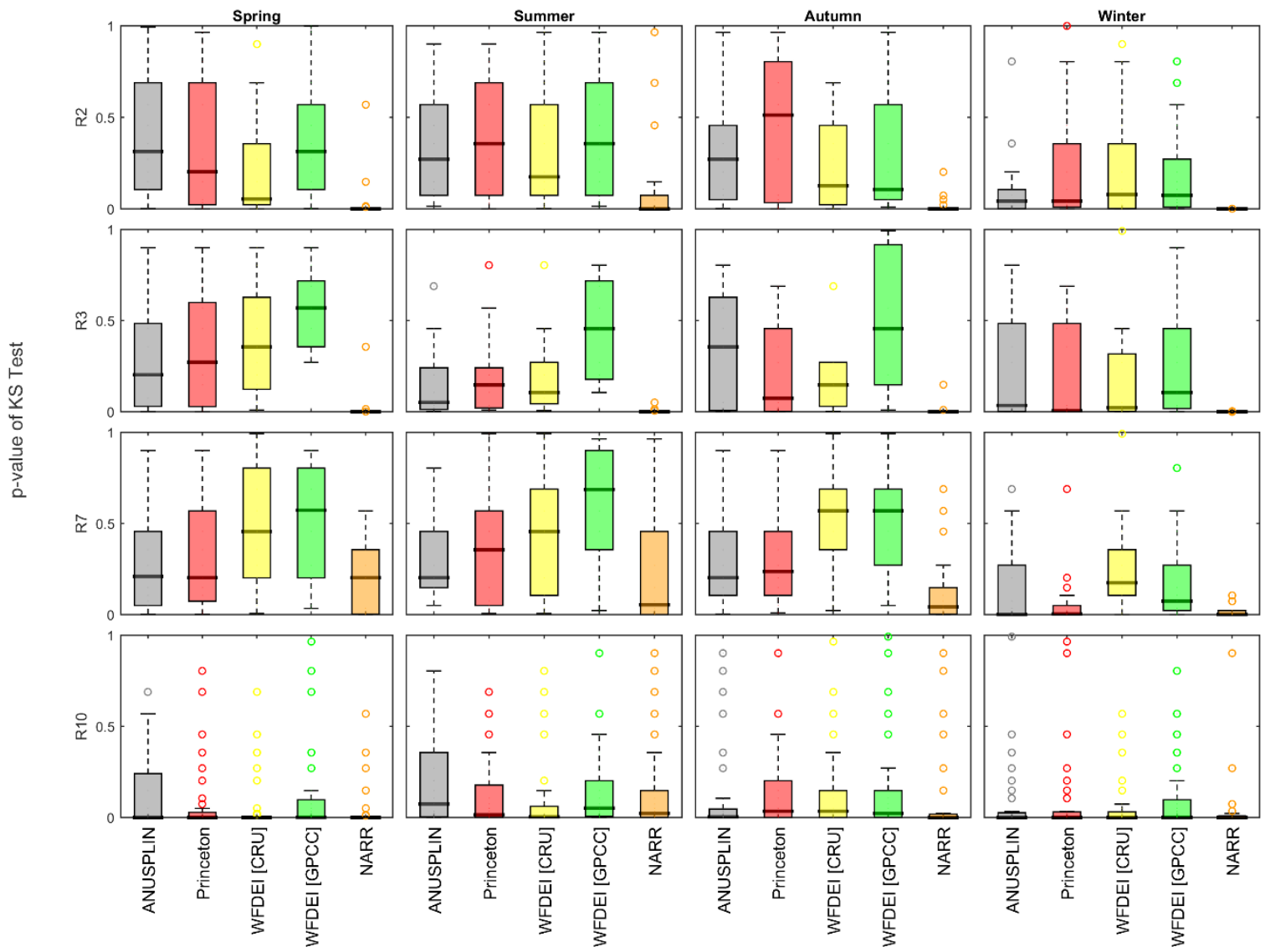

Figure S2. Distributions of p-value of the K-S test in major drainage areas in four seasons for the period of 1979 to 2012 (long-term comparison without CaPA). Note that the numbers of precipitation-gauge stations in each major drainage area are different (see Table S1). The p-values of Regions 2 to 3, 7, and 10 (R2-R3, R7, and R10), which have more than or equal to 10 stations, were only shown for illustration in box-whisker plots with bottom, band (black thick line) and top of the box indicating the 25th, 50th (median), and $75^{\text {th }}$ percentiles, respectively. 


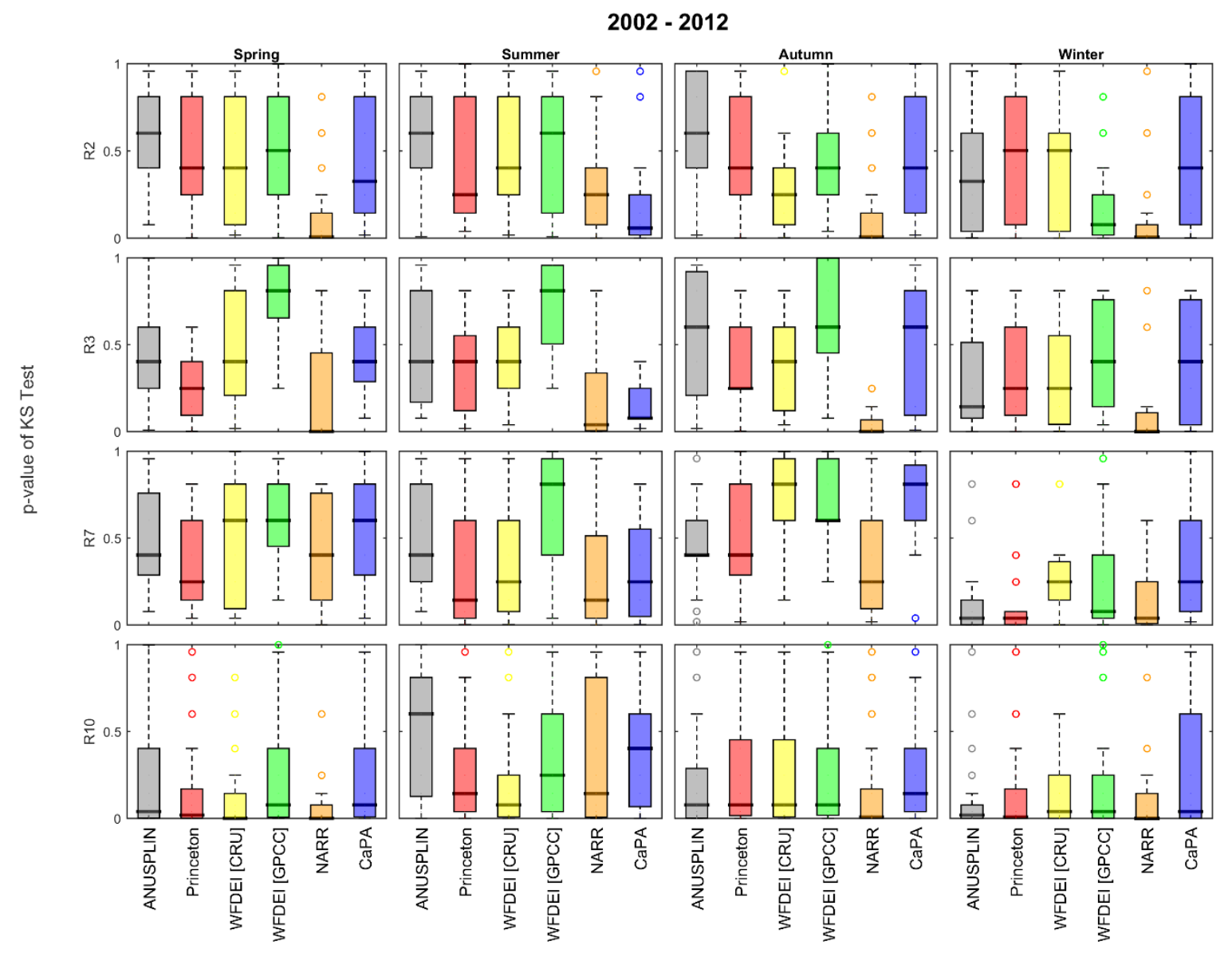

Figure S3. Distributions of p-value of the K-S test in major drainage areas in four seasons for the period of 2002 to 2012 (shortterm comparison with the inclusion of (CAPA). Note that the numbers of precipitation-gauge stations in each major drainage area are different (see Table S1). The p-values of Regions 2 to 3, 7, and 10 (R2-R3, R7, and R10), which have more than or equal to 10 stations, were only shown for illustration in box-whisker plots with bottom, band (black thick line) and top of the box indicating the $25^{\text {th }}, 50^{\text {th }}$ (median), and $75^{\text {th }}$ percentiles, respectively. 
$1979-2005$
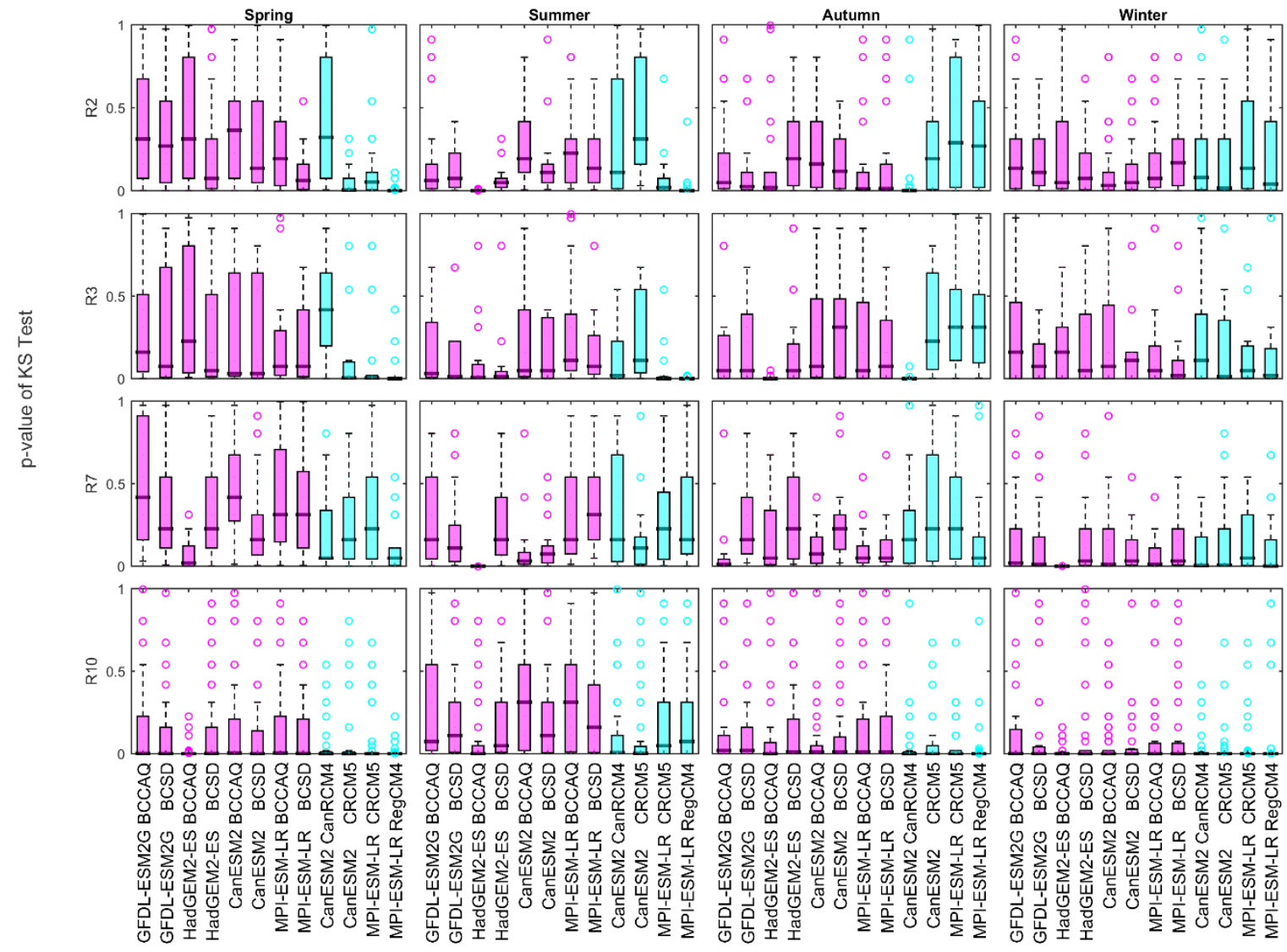

Figure S4. Distributions of p-value of the K-S test in major drainage areas in four seasons for the period of 1979 to 2005 (long-term comparison of PCIC and NA-CORDEX). Note that the numbers of precipitation-gauge stations in each major drainage areas are different (see Table S1). The p-values of Regions 2 to 3, 7, and 10 (R2-R3, R7, and R10), which have more than or equal to 10 stations, were only shown for illustration in box-whisker plots with bottom, band (black thick line) and top of the box indicating the 25th, 50th (median), and 75th percentiles, respectively. 


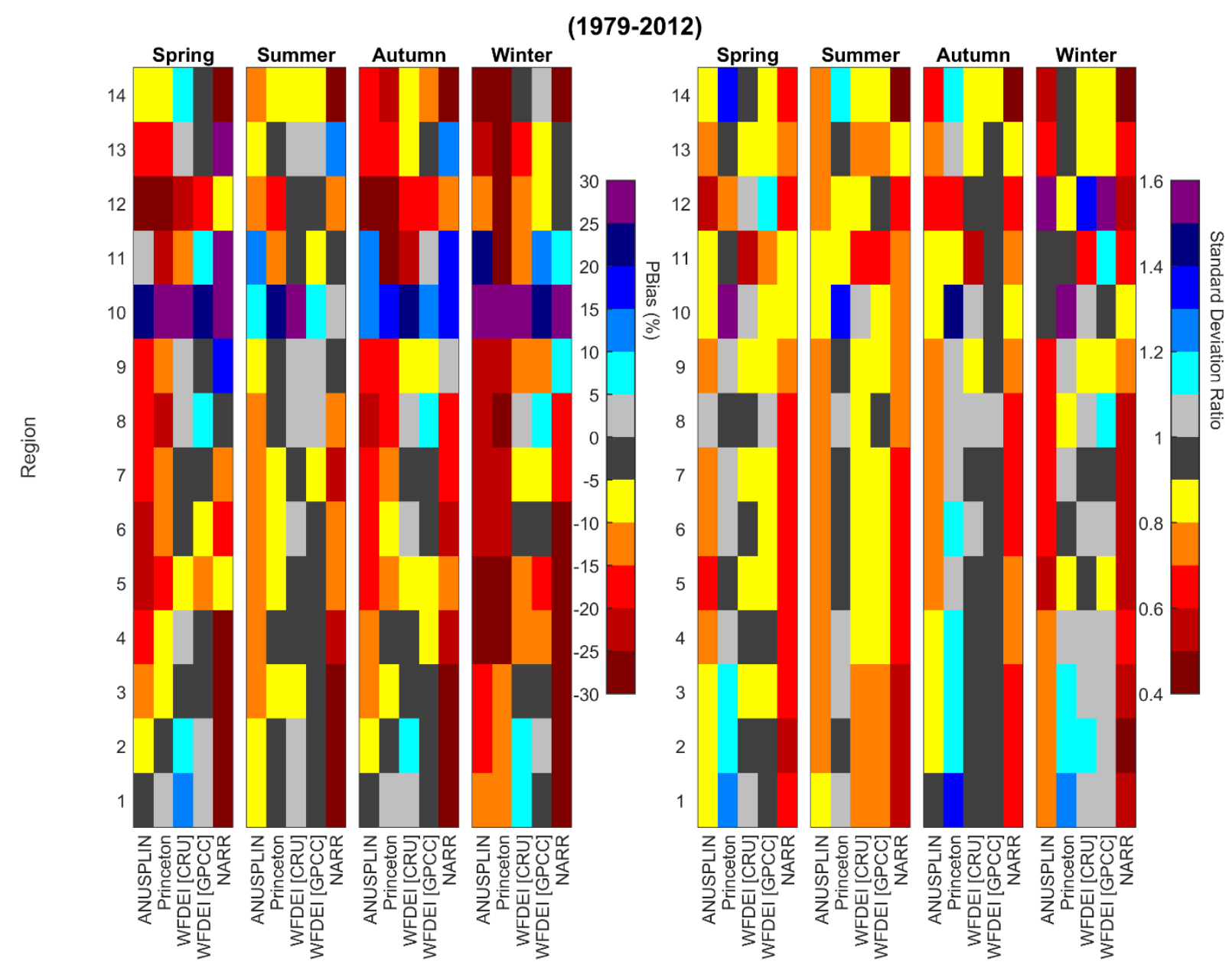

Figure S5. Portrait diagram showing the accuracy (PBias) (left) and amplitude of the variations $\left(\sigma_{G} / \sigma_{R}\right)$ (right) of each type of gridded precipitaiton products when evaluating against the precipitation-gauge station data in each major drainage area (Region 1 to 14) in four seasons for the time period of 1979 to 2012. Each column indicates one gridded precipitation product and each row represents one major drainage area with numerical code corresponding to region shown in Fig. S1. 


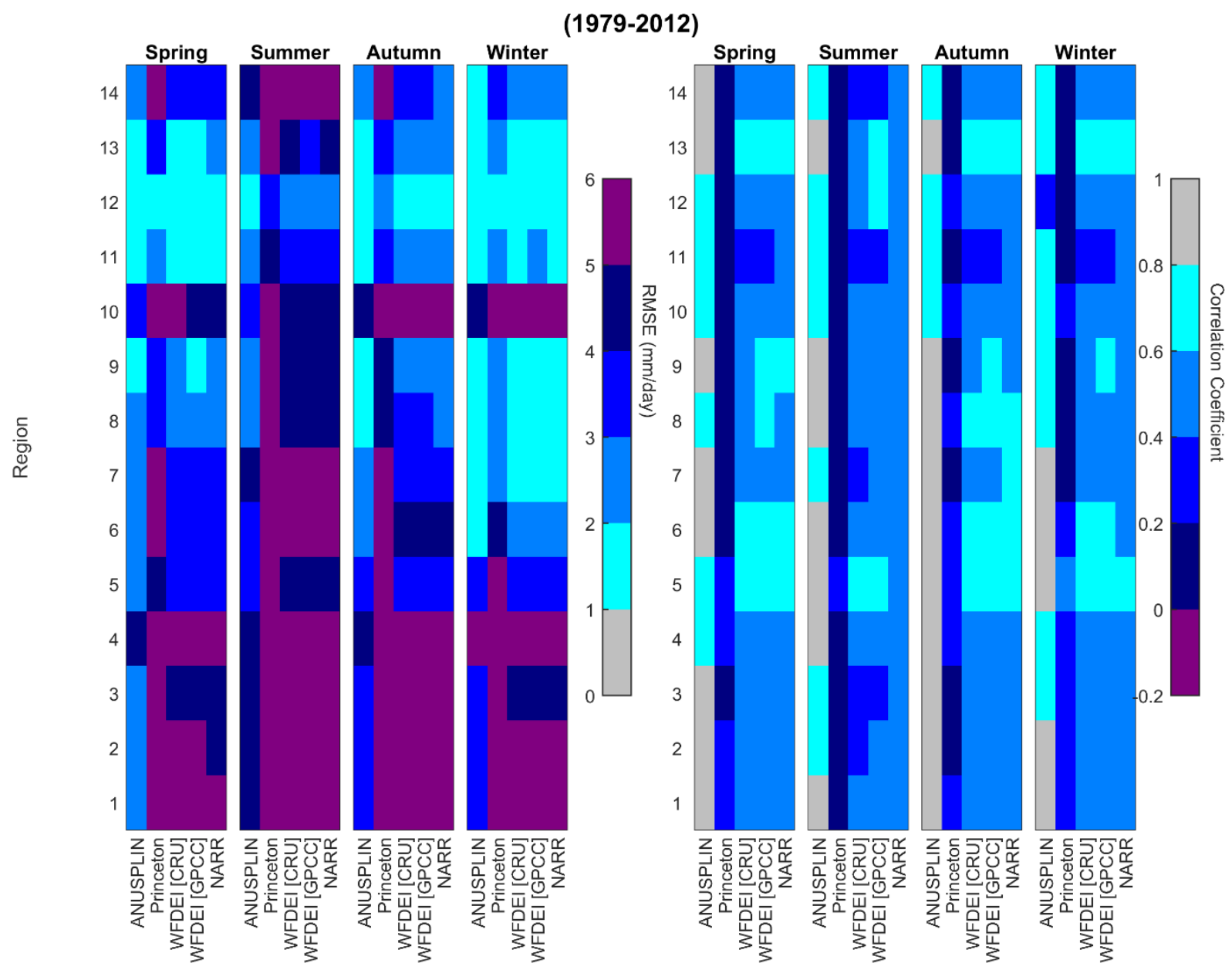

Figure S6. Portrait diagram showing the magnitude of the errors (RMSE) (left), and strength and direction of relationship between gridded products and precipitation-gauge stations $(r)$ (right) of each type of gridded precipitaiton products when evaluating against the precipitation-gauge station data in each major drainage area (Region 1 to 14) in four seasons for the time period of 1979 to 2012. Each column indicates one gridded precipitation product and each row represents one major drainage area with numerical code corresponding to region shown in Fig. S1. 